\title{
Artigo
}

Resumo
Este artigo aborda opercurso dos
modos de relação com a infância
nas diferentes épocas da bistó-
ria. Tem por objetivo discutir
as formas de inclusão e exclu-
são social da criança. A cultu-
ra promove discursos sociais
normatizadores. Abordamos o
discurso atual, que impõe uma
estreita margem de normalida-
de.
Descritores: infância;
normatização; inclusão; exclu-
são.

\section{INFÂNCIA E NORMATIZAÇÃO: LUGAR DE CRIANÇA E O DISCURSO SOCIAL DA INCLUSÃO E EXCLUSÃO}

\author{
Regina Maria Ramos Stellin \\ Luana Timbó Martins \\ Georgia Porto Triandopolis \\ Elisa Parente Costa
}

\section{Pr volta das décadas de 50 a 70 , a cidade de}

Quixeramobim, localizada no sertão do Ceará, possuía alguns mil habitantes e era bem diferente das grandes cidades de hoje. A luz elétrica apagava bem cedo, o som da "radiadora", liberado pelos vários autofalantes espalhados pela cidade, era a grande atração da tarde. Pode-se dizer que a convivência das pessoas nessa época se assemelhava à de uma comunidade. Cada cidadão era conhecido pela população com suas singularidades e havia um maior

Psicóloga, psicanalista, professora do curso de Psicologia da Universidade de Fortaleza (UNIFOR).

- $\square$ Psicóloga.

[ $\square$ Psicóloga.

口u Psicóloga. 
compartilhamento dos ambientes urbanos entre as pessoas. Não era muito visível a discrepância de classes sociais. No contexto de uma cidade isolada da capital, as condições financeiras não faziam marca de diferenças. Até porque, os valores não estavam perpassados pelos objetos de consumo. Os laços sociais se afiguravam mais intensos onde as histórias familiares faziam pertinência.

Nessa mesma época, um sujeito com o apelido de Chico Caminhão transitava pela cidade. Este era apenas uma das pessoas que possuíam o comportamento um pouco diferente do habitual e que conviviam harmoniosamente com o resto da população. Chico era um sujeito engraçado e querido por todos os cidadãos de Quixeramobim. Seu fascínio, assim como seu universo, estava nos caminhões. Tinha como lugar preferido a Praça da Estação, onde ficavam estacionados os grandes caminhões da cidade. Comum era vê-lo conversando com os caminhoneiros, e eram esses diálogos que sustentavam suas fantasias sobre essas máquinas gigantes. Por conta desse deslumbramento, Chico queria ser efetivamente um caminhão. Para ele, seu corpo era uma máquina, e sua postura era encurvada para se assemelhar ao formato do modelo que desejava parecer. Chico andava fazendo barulhos pela cidade. Quando parava para cumprimentar os amigos, fazia o som do freio. Ao reiniciar sua caminhada pelas ruas, ouvia-se o acelerador em movimento.
Das muitas histórias que os moradores partilhavam sobre Chico, o sujeito-caminhão, uma era ponto de lembrança maior. $\mathrm{O}$ evento ocorreu quando lançaram um novo modelo que o deixou fascinado, apelidado de "Marta Rocha". Entre suas características, havia o desenho de uma meia circunferência que tapava o farol do caminhão. Este design da marca levou Chico a cortar seus cílios na tentativa de ficar mais semelhante com o novo modelo. Tal ato identificatório teve como efeito, além de se sentir a própria "Miss Brasil", uma insônia por algumas noites.

O mais curioso dessa história era a convivência desse sujeito com a população. Como caminhão, tinha uma função própria a desempenhar nesse grupo. Chico vivia a carregar encomendas, como sacos de farinha, açúcar e sal. Atarefado nas entregas, fazia parte da paisagem sertaneja a labuta de seu percurso cotidiano, a carregar mercadorias nas costas. Caso demorasse a entrega, escutavam-se comentários como: "Vixe, o Chico deve estar quebrado por aí!". O que de fato acontecia. Alguns diziam que Chico descuidava da manutenção; outros, que corria demais nas curvas. Contava-se um episódio em que foi solicitada a entrega de um saco de açúcar. Chico não cumpriu o compromisso assumido. Quando localizado, estava no chão, com as pernas para cima, em meio ao açúcar espalhado. A explicação foi então traduzida pelo sujeito-caminhão: "Estou com um pro- 
bleminha aqui... Estava vindo em alta velocidade e bati em uma pedra, agora estou com o pneu furado".

A história de Chico Caminhão na cidade de Quixeramobim ${ }^{1}$ oferece uma ideia sobre a possibilidade de se ter pessoas "diferentes" no convívio natural de uma cidade. Até porque, sabe-se que este fato aconteceu antes do exacerbamento do discurso científico sobre normatização e inclusão social. Chico participava do convívio com as pessoas de sua cidade como o sujeito que queria ser caminhão. Este era seu jeito de estar no mundo, em uma singularidade que não o excluía do coletivo. Os outros não se inquietavam com suas diferenças, não buscando, portanto, que se desprendesse deste comportamento para igualá-lo à média das pessoas, em uma posição mais adaptativa. Era sua marca de subjetividade: Chico, o sujeitocaminhão, como Pedro, o marceneiro, ou Maria, a rendeira.

Contamos aqui esta história para introduzir a defesa de uma ideia, da relação sujeito/coletivo, ou melhor, subjetividade/laços sociais. Apontamos um discurso social como sustentador do lugar do sujeito. Nesta posição, o sujeito se configura em seu tempo/lugar, o que significa mudança de processo de subjetivação com a época, produzindo efeitos nos laços sociais. As mudanças neste discurso possibilitam o pensar em novos sujeitos, novos lugares sociais, outros lugares de pertinência. Mas quando instituído, o discurso sobre o sujeito se propõe em uma existência atemporal. Dá a impressão de que os sujeitos e suas relações sempre existiram na forma contemporânea, de que não fazem parte de uma construção histórica. Hoje em dia, nos parece que o discurso sobre a loucura como algo a ser tratado por profissionais especializados sempre existiu. No entanto, a história de Chico Caminhão nos mostra uma outra forma de episteme do sujeito, pela via de sua inserção em uma historicidade. Hoje, Chico estaria medicado, internado, tratado, já que deixaria de ser Chico Caminhão para ser Chico Maluco, nomeado não mais pelos parentes e amigos, mas pelo discurso científico, instaurado como fonte de verdade absoluta.

Chico encontrava-se incluído no dia-a-dia das pessoas de sua comunidade de forma distinta da que uma criança "especial" encontra-se incluída em uma escola regular atualmente. A diferença de Chico não era considerada uma patologia, não havendo então necessidade de tratamento. Ele conseguia circular, conviver, ser requisitado, ser cidadão.

O que procuramos discutir neste artigo é a questão da inclusão e exclusão no social contemporâneo, pautada num discurso norma- 
tizador sem maleabilidade. Um discurso de igualdade na via totalitária, obrigando todos a seguirem uma norma de comportamento específica se quiserem ocupar certo lugar social. Podese dizer o mesmo sobre certos discursos sociais que nos falam da infância. Nossa proposta é trilhar uma reflexão sobre uma suposta inquestionabilidade da infância como tempo de brincadeira e educação, como preparação gradual para a vida de adulto. Pretendemos, neste artigo, percorrer caminhos sobre a construção de discursos sociais que nos falam dos lugares dados às crianças: da não-existência de um sentimento de infância na Idade Média até a centralidade dos pequenos na família nuclear, da construção de uma ligação naturalizada da infância com uma educação escolar que potencializasse o seu desenvolvimento futuro, e, mais atualmente, de uma preocupação em perceber as crianças como atores sociais plenos desde cedo, com um questionamento de visões adultocêntricas anteriores.

\section{Infância, historicidade e desenvolvimento}

A Lei $n^{\circ} .8 .069$, de 13 de julho de 1990, que dispõe sobre o Estatuto da Criança e do Adolescente (ECA), explica em seu segundo artigo: "Considera-se criança para os efeitos desta Lei, a pessoa até doze anos de idade incompletos, e adolescente aquela entre doze e dezoito anos de idade." A preocupação com o desenvolvimento pleno do indivíduo aparece no terceiro artigo, que diz: "A criança e o adolescente gozam de todos os direitos fundamentais inerentes à pessoa humana, sem prejuízo da proteção integral de que trata esta Lei, assegurando-selhes, por lei ou por outros meios, todas as oportunidades e facilidades, a fim de lhes facultar o desenvolvimento físico, mental, moral, espiritual e social, em condições de liberdade e de dignidade." (1990, Art. 3).

Há, no Estatuto, uma ligação explícita entre o desenvolvimento das crianças e a educação escolar. Versa sobre o direito à educação e é afirmado no Art. 53: “A criança e o adolescente têm direito à educação, visando ao pleno desenvolvimento de sua pessoa, preparo para o exercício da cidadania e qualificação para o trabalho." Também é assegurado pelo Estatuto o direito de igualdade em relação ao acesso escolar e à obrigação de pais ou responsáveis pela matrícula de seus filhos na rede regular de ensino. O ECA (1990) estabelece ainda que "éproibido qualquer trabalho a menores de dez̧esseis anos, salvo na condição de aprendiz" (Art. 60).

O ECA (1990) veio para garantir, através da lei escrita, os direitos relativos à infância e à juventude, visando a inclusão social e o direito à cidadania. A ênfase do discurso sobre a definição de infância e adolescência está fundamentada nos aspectos desenvolvimentistas. A cronologia 
de tempo de ser criança e entrar na adolescência, e também de tempo para se tornar adulto é delimitada pela lei. Esta também afirma a obrigatoriedade dos adultos no asseguramento de condições para o desenvolvimento pleno deste sujeito. Esta proteção, marcada na modernidade por leis, nos coloca um percurso de indagações: Porque essa obrigação, garantida por lei, de que toda criança esteja na escola? Sempre houve essa ligação entre desenvolvimento pleno do indivíduo e escolas? E, para responder a estes questionamentos, torna-se necessário um breve estudo sobre a história da infância. Vamos situar o momento do surgimento desta configuração, que tem como efeito os cuidados à infância.

Autores como Colin Heywood (2004), Jurandir Freire Costa (2004) e Philippe Ariès (1986) afirmam que a fascinação pelos anos da infância é um fenômeno um tanto recente, que surgiu através de uma construção histórica. É na modernidade que infância e desenvolvimento estabelecem uma relação intrínseca entre si. Em determinada época da história, a infância passa a se configurar como um momento especial, diferente da vida adulta e na qual as crianças são percebidas como seres frágeis e moldáveis, necessitadas de cuidados e proteção, estando ainda em processo de desenvolvimento físico, moral e intelectual. Os autores supracitados formulam a história da família nuclear moderna, 
com uma nova configuração de lugares em relação à família medieval. Na nova ordem, a criança tornou-se o centro da instituição familiar. Passa a ocupar a posição de valor central na família, que na Idade Média era do patriarca. O conceito de infância é posicionado em uma historicidade.

$\mathrm{Na}$ Idade Média, o tempo de infância descrito por Ariès (1986) reduzia-se ao período em que a criança era muito pequena, necessitando dos cuidados provindos dos adultos para sobreviver. Mas ao adquirir uma autonomia básica, passava a ter funções semelhantes a dos outros indivíduos, guardadas as devidas capacidades. Passa então, a realizar pequenas tarefas no cotidiano da casa, como aprendiz dos mais velhos.

Costa (2004) também aponta estas condições no período do Brasil colonial. As crianças tinham um papel secundário nas famílias. O filho que importava era o filho adulto, que pudesse cuidar das propriedades familiares e reproduzir as tradições seculares. As crianças não tinham especificidades relacionais, habitando uma convivência comum junto aos mais velhos. A expectativa era de que ocupassem o mais cedo possível a posição de adultos, tanto em relação ao comportamento quanto ao cumprimento de tarefas.

A Tradição orienta a formação de vínculos na família antiga. $\mathrm{O}$ chefe de família tinha valor social como patriarca na sustentação e reprodução dos bens materiais herdados de seus ancestrais, sendo o guardião do patrimônio. Na sociedade colonial, a missão da família, mais especificamente do patriarca, era proteger as propriedades dos ancestrais e assegurar o lugar de senhores, pois os que não possuíam estas propriedades eram servos ou escravos. Assim, o papel masculino era o de protetor e patrão da família, com seu saber sustentado pela Tradição. Seu poder é legitimado, estando os outros membros familiares em função deste patriarca.

Os laços afetivos entre pais e filhos não eram necessários nesta vida regida pelos costumes. Vários autores que tratam dos laços sociais antigos apontam que o sentimento familiar circula na posição de manutenção de patrimônio. Desta maneira, a afetividade entre cônjuges e entre os pais e os filhos não era necessária à existência nem ao equilíbrio da família. Os cuidados com os pequenos ficavam a cargo de amas de leite, que permaneciam com estas até que tivessem independência suficiente para funcionar no meio familiar. Isso desde que sobrevivessem a este primeiro período de fragilidade, já que era alto o índice de mortalidade infantil. Os relatos extensivos 
sobre as crianças da família medieval contam de sua permanência na casa patriarcal até os sete ou nove anos. Após essa idade, os pequenos eram encaminhados como aprendizes para outras casas. Tinham como tarefa aprender o serviço doméstico e servir a um mestre. A educação era realizada na convivência do cotidiano junto aos adultos. Aprendiam o que se esperava deles na circulação dos afazeres junto aos mais velhos.

Havia uma inexistência de direcionamentos específicos às crianças, não voltados a uma capacidade de entendimento singular, já que não havia um reconhecimento de limitações existentes em etapas do desenvolvimento infantil. Portanto, ainda não existia a ideia desenvolvimentista na constituição do sujeito, ou seja, de infância como uma idade de preparação para a vida adulta.

Heywood (2004) é um autor que se baseia na sociologia infantil atual para afirmar que a infância é uma construção social, que pode ser compreendida de formas distintas nas diferentes épocas e sociedades. Segundo Heywood (2004): "Atualmente, no ocidente, acabamos realmente por associar a infância, em termos gerais, a características como a inocência, a vulnerabilidade e a assexualidade, enquanto pessoas em lugares como, digamos, as favelas da América Latina ou as regiões devastadas pela guerra da África, não o fariam.” (p. 12).

A defesa deste autor é de uma infância entendida como qualidade temporal, situada em um contexto social e cultural. O autor considera também que a possibilidade de saber sobre a história do sentimento de infância é dificultada pela ausência de material a ser estudado, supondo que os artefatos específicos do mundo infantil pouco sobreviveram. Além disso, a documentação possível sobre o tema vem, na Idade Média, da classe letrada, geralmente aristocracia ou religiosos, já que a grande massa camponesa permanecia analfabeta.

Os autores divergem sobre a existência de um sentimento de infância neste tempo. Ariès (1986) afirma sua não-existência pela indistinção entre criança e adulto, em uma época de ausência de particularidades designadas ao sujeito dos primeiros anos de vida. Heywood (2004), de outra forma, sugere que esse sentimento era apenas percebido de forma diferente. Sustenta que sempre houve uma diferenciação entre adultos e crianças, mas que as formas dessa diferenciação mudam no espaço e no tempo. Assim, essas noções de fragilidade e inocência infantis são específicas de certos períodos em alguns lugares, e o fato da não-valorização do tema pelos autores medievais aconteceria por uma posição diferente frente ao entendi- 
mento de como um indivíduo se desenvolve até a vida adulta.

Para os medievais, os primeiros anos de vida não teriam relação com o posterior caráter adulto. Não há, neste período, uma ideia desenvolvimentista relacionada ao sentimento de infância. Heywood (2004) coloca que a natureza das crianças na Idade Média seria determinada por sua classe e gênero, e não pelas experiências individuais. Dessa forma, acreditava-se que "se um menino de origem nobre viesse a ser adotado por camponeses ou comerciantes, sua verdadeira natureza viria à tona, à medida que ele, inevitavelmente, reagisse contra um ambiente inadequado" (p. 52).

A necessidade de proteção e educação moral para as crianças surgiu juntamente com o reconhecimento de uma evolução no desenvolvimento dos sujeitos, prevendo que as experiências individuais de uma criança influenciariam na vida adulta. Reconhecimento este que pôde ser realizado a partir da modernidade, com a noção de indivíduo. Foi a partir desta nova configuração relacional que o adquirido ganhou espaço em relação ao inato. As elites voltam sua atenção à criação dos jovens, procurando orientações proporcionadas por moralistas. $\mathrm{Na}$ tentativa de entender essa leitura desenvolvimentista na infância, é necessário que discorramos sobre algumas mudanças que ocorreram nas sociedades ocidentais desde a época medieval até a modernidade. 


\section{Passagem para a Modernidade: a mudança de discurso}

Os discursos sociais que regem os laços e organizam as relações são orientados pelo saber vigente. Façamos um percurso do saber teológico ao científico. Esta mudança de leitura do mundo pode ser produzida a partir do momento em que um discurso sustentador passa a sofrer questionamentos, implicando na quebra do saber monolítico, e assim começando a apresentar fissuras, dando passagem a uma nova configuração no olhar sobre a civilização e suas formas de orientação.

$\mathrm{Na}$ Idade Média, o pensamento vigente era marcado pelo dogmatismo religioso, através do qual tudo se explicava pela vontade divina. O cristianismo vinha se consolidando na Europa desde o século IV. As respostas estavam todas dadas pela ideia de que a vida era comandada por Deus, e assim os sujeitos não precisavam mover-se em busca de uma verdade própria. Figueiredo (2002) afirma que, durante o século XVI, as margens e fronteiras eram nítidas e as identidades duráveis. Era um mundo fechado, não havendo lacunas ou vazios, e as experiências eram preenchidas de sentido e valor. $\mathrm{O}$ mundo estava posto, e o que rompia suas barreiras era entendido como pecado.

A economia feudal também não dava espaço para uma mobilidade social. Os sujeitos nasciam dentro de uma classe e nela ficavam por uma questão de ancestralidade. Portanto, nessa época, uma geração passava à outra sem muitas mudanças, seguindo os passos dos seus antecedentes, mantendo a mesma ocupação e posição social.

No século XVI, o saber científico que começa a ser sistematizado, começa a indagar o saber teológico, sustentador até então da posição do homem no mundo. Fissuras vão se abrindo junto com as grandes navegações, que trouxeram um grande aumento do comércio entre os povos. Esta possibilidade de trocas interculturais aumenta as veias abertas da teologia, sopra novos ventos a favor da instalação de um outro olhar.

Entre o século X e o fim da Idade Média houve uma grande explosão demográfica na Europa. Este aumento populacional foi garantido pela segurança contra invasores e pelo crescimento do comércio. Embora a ordem social permanecesse fixa, novas profissões surgiam: além dos padres, guerreiros e camponeses, passam a 
existir advogados, contadores, artesãos, funcionários administrativos, entre outras.

Figueiredo (2002) afirma que, no final da época medieval, existia um sentimento de horror às margens, visto que as fronteiras traziam sempre algo de novo, como o contato com formas bem diferentes de alteridade. Este horror tenta sustentar um saber conhecido, mas já exaurido. Afirma, pela resistência, a instalação de um novo saber. A mistura das civilizações trouxe a ideia de contágio, e a civilização cristã sentiu-se então ameaçada. Os clérigos passaram a fazer um trabalho de reforço da identidade da cultura europeia. Os conversos e os hereges constituíam-se em ameaça. Os primeiros porque corriam o risco de não ter entrado inteiramente no autêntico cristianismo. Os segundos por serem transgressores de limites. A defesa contra estes males foi, por um lado, o fanatismo intolerante e puritano, representado no movimento da Inquisição, levando os considerados hereges à fogueira. Por outro, a busca por novas formas de relacionar-se com a ideia de Deus. Dessa forma foram abertas as portas para a grande Reforma protestante.

A Reforma protestante do século XVI surgiu para preencher o perigo de uma ausência de sentido e as ameaças de aniquilamento e destruição das identidades. Martinho Lutero (1483-1546), um dos reformadores, defendia uma liberdade maior na experiência religiosa, uma vivência individual da fé, um contato direto do homem com Deus. Em um mundo pleno de sentidos, não seria necessário se propor uma reforma, como não existia mobilidade social, as pessoas não se questionavam sobre sua identidade, tudo estava dado: as crianças seguiriam a profissão do pai e assim sucessivamente. Não era preciso pensar sobre o futuro ou sobre a importância dos pequenos quando o que importava já estava escrito pela vida dos antepassados. No entanto, a insatisfação com o modo vigente de pensar o mundo abriu questionamentos, na busca de um novo ordenamento das ideias políticas, religiosas e culturais. Com a Reforma surgiram ideias que tentavam dar sentido à forma que o homem deveria se relacionar com o mundo e com sua liberdade, mas as explicações teológicas já não satisfaziam à curiosidade do homem. Abriu-se espaço para uma concepção diferente, que se relacionasse com a observação empírica do mundo. As ideias abriram um percurso em direção a verdades científicas, estabelecendo o primado da razão.

René Descartes (1596-1650), filósofo que dedicou seus estudos à produção de um método que seria capaz de eliminar todos os 
preconceitos, contribuiu para essa revolução no pensamento humano. Descartes só acreditava na razão como fonte de verdade, ou seja, como construção de saber. Na busca de uma ciência universal, uma verdade absoluta, chegou a duas regras de operação mental necessárias para a aplicação do seu método. Uma, a intuição, iluminada unicamente pela luz da razão. Outra, a dedução, que seria a afirmação da verdade de uma proposição em decorrência de outros fatos tidos como certos. A aplicação correta dessas duas regras de pensamento ficou conhecida como Método Cartesiano.

O Discurso do método (Descartes, 1983), foi o trabalho que mudou a história da filosofia. Nele, o autor descreveu minuciosamente como desenvolveu seu pensamento e expôs diversas ideias que foram atingidas pelo seu método. Ele nos mostra como é possível, em um exercício da razão, destruir todas nossas crenças sobre o mundo que nos rodeia se nos guiarmos por uma dúvida reflexiva e persistente. Assim chega a uma única certeza: o ato de pensar. Para esse filósofo, só isso provaria sua existência. Descobrindo que é possível duvidar de tudo, Descartes acabou levantando questões sobre a própria existência de Deus.

Junto a Descartes, Francis Bacon (1561-1626), um dos fundadores da ciência moderna com o empirismo e estudos filosóficos sobre a metodologia científica, desenvolveu à sua maneira projetos de "cura da mente", resultando em uma rachadura na subjetividade do homem moderno. De um lado, a confiável e previsível 'objetividade', de outro a volúvel, isolada e privatizada 'subjetividade'. Acreditava que, retirando-se as fontes de variações existentes no homem poderse-ia ter a constituição do sujeito epistêmico com verdadeiras condições de representação do mundo. A divisão cartesiana do sujeito entre corpo e mente impulsionou ainda as experiências ligadas à fisiologia e à anatomia, que agora podiam dispor de cadáveres para seus estudos, já que a "alma" não estava mais inseparável do corpo.

John Locke (1632-1704) contrapõe o empirismo ao racionalismo de Descartes, pois baseava o conhecimento da verdade por meio da experiência (sensação, prazer, interesse). A burguesia, camada social que se destacava pelo seu crescimento econômico e político, tem parte de suas ideias representadas no empirismo, pois buscavam uma possibilidade de mobilidade social baseada nas experiências de vida e não na ideia de lugares predeterminados por uma ancestralidade nobre. Em relação à infância, é importante ressaltar que Locke trouxe a imagem da criança como sendo uma "tábula rasa". Tal ideia ia contra a doutrina do pecado original e reforçava a importância da educação na formação do caráter adulto.

Jean-Jacques Rousseau (17121778) vai adicionar a esta ideia de in- 
fantil, a inocência original das crianças, o que a coloca padecendo nas mãos de uma sociedade contaminada pelos preconceitos e autoridades. Sua teoria, apontando para uma infância "pura" e que não deve ser contaminada pelos adultos, influenciará mais tarde a pedagogia moderna (conhecida como "escola nova", em contraposição com a pedagogia tradicional), já colocando que as crianças devem ser educadas de modo mais livre, experimentando seus sentidos e emoções infantis, e não de forma tão regrada pelos adultos.

Já na segunda metade do século XVII, o Iluminismo surge como um movimento intelectual que tinha a razão e a ciência como forma de se compreender o mundo. A defesa do racionalismo toma tal extensão que $\mathrm{o}$ século XVIII denomina-se o "século racionalista", o momento em que, pela primeira vez, o sol da razão iluminou a humanidade, até então envolta nas trevas da fé e da autoridade. Os iluministas acreditavam que somente pela razão se poderia explicar as coisas do universo. A ciência passa a ser considerada como o único meio para alcançar os fins humanos, em uma confiança absoluta na razão, engendrando uma nova mentalidade humana. Para os iluministas, cada um teria o dom de pensar por si mesmo, e as ideologias não deveriam mais falar pelos homens.

A ciência moderna pôde surgir quando a ideia de Deus perdeu sua soberania, deixando o espaço aberto 
para uma verdade a ser produzida pelos próprios sujeitos. Como se pode perceber, na modernidade houve um deslocamento da verdade, de um exterior (Deus) para uma interioridade (indivíduo). Chauí (2002) explica a considerável contribuição de Immanuel Kant, no século XVIII, para a ciência e para a filosofia. Foi Kant (1724-1804) quem enfatizou a importância de todo filósofo conhecer, antes de tudo, a razão, e o que ela pode ou não conhecer, para depois voltarse sob a realidade e os objetos de conhecimento. Para este filósofo a razão é uma estrutura inata a todos os indivíduos, não é adquirida pela experiência, e por esse motivo é anterior ao contato com o objeto de conhecimento. Dessa forma, a razão tem como função, regular e controlar a sensibilidade e o entendimento do homem para que este possa apreender os conteúdos de sua experiência.

O racionalismo kantiano colocou mais ainda a razão no centro do pensamento humano, contribuindo para essa ideia de um sujeito laico, separado de Deus. Dessa forma, a base para se chegar ao conhecimento passa a se fundamentar exclusivamente na razão e na ciência. Deus perde esse lugar fundamental para a compreensão do mundo, dando lugar ao homem como o centro do universo. Nessa mesma época surge a burguesia com novos valores e novos questionamentos. $\mathrm{O}$ efeito é uma mobilidade social que desconstruirá as formas de laço sustentadas por tantos séculos. 
O Iluminismo, ao propor a libertação econômica, intelectual, e social, retirando o sujeito da escuridão, inspira os ideais da Revolução Francesa. As ideias iluministas de liberdade, igualdade e fraternidade passaram a fundamentar os laços da sociedade ocidental. O contrato social do Estado Moderno coloca todos em uma mesma posição lógica juridicista, onde "a lei é igual para todos". Enfatiza a ideia de que todos teriam as mesmas oportunidades.

A constituição da subjetividade moderna sofre influência desse processo de conquista da liberdade que é impulsionado pelas ideias iluministas. Essa nova visão de mundo envolvia a ideia de que o sucesso na vida dependeria exclusivamente da ação de cada um e não de uma vontade divina. Com Deus fora de cena, o indivíduo teria que fazer suas próprias escolhas, tendo que voltar-se para suas experiências pessoais.

Dessa forma, é somente na modernidade que a noção de indivíduo pôde emergir como categoria de subjetivação. E essa noção deu espaço a uma preocupação com a interioridade, já que, em vez de buscar as respostas em Deus, todos deveriam voltar-se para si mesmos. Portanto tornava-se necessária uma educação desde a infância, que preparasse as crianças com base em experiências individuais para uma vida adulta moralmente saudável. Ferretti (2004) afirma que "a ideia de que a criança não é um adulto em miniatura, mas um adulto em potência, mostra a crença e a esperança de que haja uma saida, pois a educação implica numa transformação" (p. 39).

Nesse contexto da valorização e do respeito ao que é privado, as experiências mais íntimas e singulares dos indivíduos assumem um novo valor e recebem formas diferentes de expressão. $\mathrm{Na}$ Europa ocorre uma valorização da dinâmica familiar. Desde o espaço geográfico, com a separação dos cômodos da casa em espaços privados, até aos aspectos relacionais enfatizando a importância que se passou a atribuir à mãe e à criança. Consequentemente, a infância passa a ser tomada como um importante período de subjetivação. Todas essas questões estão relacionadas com as novas formas de cuidados de si que modificaram as relações mais íntimas do homem moderno. Neste momento o que interessa é enxergar mais além. Agora, a subjetividade privada se exterioriza e passa a ter uma nova importância. Essa privacidade vai abrir espaço ao que é mais íntimo do homem, o 'psicológico'.

A partir do século XIX, a ciência passou a influenciar diretamente o comportamento social. Costa (2004) traz a ideia de que a ciência moderna passou a ser utilizada como estratégia da política para disciplinar a população. Segundo Foucault (1987), na modernidade surge a disciplina como um método que permite o controle minucioso sobre as operações do corpo dos indivíduos, realizando a sujeição constante de suas forças e impon- 
do a relação obediência-utilidade. A disciplina marcou uma mudança no eixo da individualização. $\mathrm{Na}$ sociedade feudal, não havia mobilidade social e a propriedade de terra indicava riqueza, autoridade e poder. O nome da família e sua genealogia situavam o indivíduo em relação aos seus parentes, e seus feitos eram imortalizados através dos relatos. Nessa época, a individualização se dava de modo "ascendente", tendo como ponto de referência os ancestrais que eram marcados por suas proezas. $\mathrm{Na}$ disciplina, a individualização se dá de forma "descendente": o poder é exercido de cima para baixo, de modo silencioso. Desta forma, ele tem efeito sobre os homens, individualizando-os através de suas fiscalizações e de suas observações permanentes, tendo como ponto de referência a "norma", que é marcada pelos desvios.

Foucault (1987) ressalta ainda que a disciplina trouxe a ideia de linearidade do tempo, de que o tempo seria evolutivo, no sentido de que o passado determina o presente, que determina o futuro. Este saber, aplicado ao ser humano, traz a preocupação com a constituição do sujeito, já que a infância passa a ser entendida como uma etapa da vida que influenciará na idade adulta. A temporalidade disciplinar coloca infância e idade adulta como uma continuidade. A criança entendida como matriz do adulto justifica o uso de técnicas disciplinares na infância, pois estas seriam necessárias para gerar adultos disciplinados.

Costa (2004) explica que a medicina higiênica, no século XIX, utilizando-se de técnicas disciplinares, encontrou espaço de intervenção junto às famílias, devido à preocupação com a alta taxa de mortalidade infantil e com as epidemias que dizimavam a população. Estes fenômenos foram atribuídos pelos higienistas aos maus cuidados das famílias para com as crianças e a condutas familiares anti-higiênicas. $\mathrm{O}$ autor fala de uma pedagogia médica que, valendose das precárias condições de saúde, passou a impor às famílias uma educação física, moral, intelectual e sexual. A antiga tradição que ditava a maneira de agir das famílias, dando prioridade à vida adulta e esquecendo-se das crianças, havia de ser combatida. Os fracos laços afetivos entre pais e filhos seriam a causa da mortalidade dos pequenos. Corpos mal cuidados, física e moralmente, seriam culpados pela propagação de doenças. Desta forma, a higiene, ao alterar o perfil sanitário da família, modificou também sua feição social. Contribuiu, junto com outras instâncias sociais, "para transformá-la na instituição conjugal e nuclear característica dos nossos tempos" (p. 12). 
A família higienizada traz um papel essencial para todos os membros. Ao pai cumpre trabalhar e suprir materialmente o lar, deixando de sugar o trabalho escravo. A mãe passa a ter a função de cuidar e educar os filhos pequenos, não os deixando nas mãos de uma ama de leite; e às crianças cumpre servir não mais à família e ao poder paterno, mas à nação e à sociedade. Saindo da tradição familiar, o que a ordem médica produz é uma norma familiar. Com a perda dos antigos valores, resta à família buscar o auxílio de especialistas que revelem seus excessos e faltas. Os agentes de normatização são encarregados então de reeducar as famílias, disciplinando seus membros.

Além do trabalho no interior dos lares, para haver um controle dos corpos na sociedade, os indivíduos deveriam ser fixados em lugares de fácil reconhecimento mediante a criação de locais físicos e sociais, nos quais toda a população pudesse ser observada e se observar mutuamente. A ideia de utilidade é prioridade em uma sociedade disciplinar. Todos devem ter uma função, tudo deve remeter a uma ordem. Foucault (1987) fala de um "quadriculamento disciplinar", que coloca "cada indivíduo no seu lugar; e em cada lugar, um indivíduo" (p. 123). Possibilitando saber como e onde encontrar cada um. Mais ainda, saber o que cada um está ou deveria estar fazendo no momento. Assim, para acabar com o caos da sociedade medieval, tornando seus membros úteis e obe- dientes, são criados lugares sociais que amarram os sujeitos em um funcionamento específico, além de uma padronização de comportamentos adequados à saúde e à felicidade. E dessa forma, a responsabilidade pela saúde da população passa a ser de todos, sendo que cada um deveria estar vigilante em relação ao seu próximo, reprimindo comportamentos que fugissem dos padrões higiênicos.

Bons hábitos de disciplina deveriam ser trabalhados. Desta forma, o primeiro alvo desta educação higiênica seriam as crianças, seres ainda moldáveis em seu desenvolvimento. A ideia de preocupação com a infância surge então desta separação entre indivíduos frágeis, que deveriam ser protegidos de más influências morais, e adultos, já impregnados por maus hábitos. Como foi dito, a prevenção na infância geraria adultos disciplinados, que então poderiam tomar as rédeas de suas vidas novamente, sendo que agora uma vida higienizada.

A infância, antes reduzida à idade em que as crianças eram totalmente dependentes, foi ampliada e separada do meio adulto, dando um tempo maior para que os pequenos se preparassem para uma vida futura moralmente saudável. A partir daí a organização familiar começou a girar em torno das crianças, e a mortalidade infantil passou a diminuir. Ressaltando que, segundo Heywood (2004), a preocupação com o futuro das nações emergentes trouxe a necessidade de se cuidar da saúde, da educação e da 
moral das novas gerações. No século XIX, fortaleciam-se as grandes nações e surgia a ideia de população como riqueza demográfica de um país. A vida e a saúde da população serviriam assim ao bem da nação. E dessa maneira, a política teria de se ocupar do desenvolvimento dos indivíduos.

Os padrões de boa conduta higiênica foram estabelecidos pelos médicos como o caminho a ser seguido para alcançar a saúde do corpo, o prolongamento da vida e da felicidade. Aqueles que não seguissem esses padrões continuariam sofrendo com epidemias e mortalidade. Costa (2004) afirma que a intervenção dos higienistas se deu principalmente com as famílias de elite, pois era necessário que existissem ainda os exemplos de antinorma, famílias infratoras da higiene médica e que por isso sofreriam as consequências: os escravos e miseráveis.

A higiene pública vai levar em consideração as classes sociais para tratar os indivíduos. Uma mulher da alta sociedade terá direito a todos os cuidados, enquanto a mulher pobre será tratada de acordo com as "regras da vida". Quando a normatização dos comportamentos aparece, os que se conformam e se adequam, reproduzem-na, e os que se rebelam servem de antinorma, justificando uma repressão. A norma produz então tanto conformistas quanto delinquentes. A higiene buscava um corpo forte, sexual e moralmente regrado, e em contraposição com este corpo higienizado precisavam existir exemplos de corrupção que demonstrassem ainda mais a necessidade da regra. Visto que a família era percebida como um fator patogênico pelos higienistas, os colégios passaram a ser o lugar de preferência para os educandos. Assim, o ensino tornou-se uma forma de isolar as crianças durante seu período de formação moral e intelectual.

\section{Escola como o lugar social da infância}

O surgimento das instituições escolares está intimamente ligado à criação da infância, tornando comum, na configuração da modernidade, a frase "lugar de criança é na escola". Ou seja, entende-se que o lugar da infância na sociedade ocidental passa necessariamente por uma educação escolar.

Ariès (1986) nos conta que, a partir do século XV, as relações familiares foram mudando. Os pais já não mandavam seus filhos para outras casas como acontecia na Idade Média. A escola, que antes era reservada somente aos clérigos, tornou-se um instrumento de iniciação social, que marcava a passagem da infância para a vida adulta. Isso aconteceu porque os educadores acreditavam que um rigor moral era necessário a fim de que as crianças resistissem às tentações do mundo adulto e pudessem preservar sua inocência. Começava a 
surgir a ideia de etapas de desenvolvimento com a noção da possibilidade de moldar os indivíduos ainda pequenos para que se tornassem adultos saudáveis.

Além disso, com a valorização do infantil e com a inclusão da afetividade nos laços familiares, os pais começaram a se preocupar com seus filhos e queriam mantê-los mais próximos, passando também a se preocupar com sua educação e sua carreira. Apesar de se afastarem da família no período escolar, esse distanciamento era diferente do ocorrido na Idade Média, pois os pequenos voltavam para casa ao término dos estudos. Os pais começaram a requisitar escolas mais próximas de suas casas para que seus filhos não precisassem ficar longe durante muito tempo. A civilização moderna é então marcada pelo estabelecimento da escola como forma de educar. Então, a educação toma lugar de pertinência social infantil, ou seja, de inclusão.

Entre o fim da Idade Média e os séculos XVI e XVII, a educação ainda era marcada pelos tratados de cortesia, pelas regras morais, pois o mundo adulto se transmitia através dos contatos humanos e das conversações. O que existia era um sistema de aprendizado familiar, caracterizado por um grande conservadorismo, passando tradições de geração em geração, através da experiência dos mais velhos. Heywood (2004) lembra que as escolas começaram a isolar as crianças do mundo adulto a partir dos séculos
XVI e XVII, mas que entre as classes econômicas inferiores, o tipo de educação familiar permaneceu sem mudanças até o século XIX.

Somente a partir do século XVIII, a família começou a se confinar em um espaço limitado e a se distanciar da sociedade. A casa se tornou um lugar de defesa contra o mundo. A cisão público/privado garantia certa liberdade de comportamento para indivíduos dentro de um ambiente específico: sua própria casa. As modificações na arquitetura possibilitaram a independência dos cômodos através de um corredor de livre acesso, valorizando mais ainda a individualidade. A família se reduziu aos pais e às crianças, permitindo uma intimidade cada vez maior. Os criados, os amigos e os clientes ficaram fora da reorganização da casa e de seus costumes devido à criação de espaços determinados. A saúde e a educação passaram a ser as duas maiores preocupações dos pais em relação às crianças, bem como a igualdade entre os filhos, pois a desigualdade passou a ser considerada uma injustiça intolerável. Esse ideal de igualdade, como já foi dito anteriormente, surge com as mudanças sociais ligadas ao Iluminismo.

Ainda no século XVIII, surgiram os primeiros sistemas nacionais de educação na Europa. Os educadores, seguindo os ideais iluministas, acreditavam na redução da criminalidade, na maior produtividade dos trabalhadores e na introdução de valores morais 
por meio da educação. Igualdade de oportunidades passou então a ser equiparada com a educação escolar. O lugar da infância passou a ser a escola, na qual a disciplina desde cedo traria o adestramento do corpo, no espaço e no tempo, a regulação do sexo e o aprendizado intelectual e moral, buscado pelos higienistas.

Ariès (1986) afirma a disciplina rigorosa como a marca de diferença entre o ensino medieval e o do colégio moderno. A arquitetura dos colégios se organiza dentro dessa ordem disciplinar moderna, com a qual o professor consegue ver todos os alunos da sala devido à disposição das cadeiras, e assim pode passar tarefas simultâneas, permitindo uma nova economia do tempo na aprendizagem. A ideia desenvolvimentista passou então a ser colocada em prática nas salas de aula, separando-se os alunos por faixa etária. Antes esta economia não era possível, pois, até o século XV, os alunos ficavam misturados, independente de sua idade e de seu grau.

$\mathrm{Na}$ Idade Média, os alunos eram separados no máximo por grau de instrução, não importando suas idades. Somente a partir do século XIX, com a linearidade do tempo aplicada ao desenvolvimento humano aconteceu a homogeneização das salas de aula por faixa etária. O aprendizado gradual de acordo com o desenvolvimento infantil se tornou importante para evitar o risco de contaminação moral dos mais novos pelos mais velhos. E, a partir daí, pôde surgir tam- bém a noção de um mestre para um grupo de alunos em um determinado grau. O que havia então era uma noção de fragilidade das crianças menores, trazendo um sentimento de responsabilidade moral dos mestres para com a infância, pois a ideia era que "o novo homem e a nova sociedade começariam a ser construidos no colégio" (Costa, 2004, p. 181).

O tempo também passou a ser ritmado pela e para essa ordem, sendo tudo fixo: hora de acordar, de comer, de estudar, de se exercitar e até de descansar. O lazer ganha espaço como obrigação higiênica para com a saúde, como descanso do trabalho. Foucault (1987) afirma que, ao fixar o tempo, pretende-se garantir sua qualidade, pois esse controle ininterrupto certificará sua utilidade. Costa (2004) coloca que o surgimento dessa noção de utilidade do tempo possibilitou que ele fosse, a partir de então, desperdiçado com o ócio. Defende que foi a higiene médica que preparou o terreno para a regulamentação do progresso intelectual na sociedade brasileira pós-colônia. Ariès (1986) ressalta que, na Europa, ainda no século XVIII, o trabalho de moralização realizado pela Igreja, pelas leis e pelo Estado, já estava envolvido com o movimento da escolarização. O primeiro afirma uma infância "reduzida" aos colégios, enquanto o segundo aponta um "enclausuramento" das crianças a partir da modernidade. Ao se criar uma época de estudos obrigatórios, uma divisão clara entre adultos e crianças 
pode ser percebida: separaram-se os que trabalham dos que apenas estudam. As crianças são retiradas do mundo do trabalho para se preparar para a vida adulta, tornando assim a escola o lugar de pertinência infantil. "Lugar de criança é na escola". Retidas na escola, podem se especializar para seguir uma carreira e futuramente fazer parte da vida social.

Heywood (2004) ressalta que as famílias camponesas se interessavam pela educação dos filhos, mas de uma forma diferente do Estado. E assim começa o que o autor se refere como sendo uma "ditadura educacional": "observadores aristocratas na Europa costumavam se referir à 'hostilidade' ou 'indiferença' dos pais com relação à educação, sugerindo, no século XIX, que a nova classe trabalhadora era incapaz de criar seus filhos de forma responsável. A implicação disso era de que as escolas e seus professores teriam de assumir algumas dessas funções" (p. 214).

As escolas passam então a assumir funções que eram da família, sugerindo um efeito benéfico na separação entre crianças e adultos. $\mathrm{O}$ autor afirma que a legislação educacional veio "de cima para baixo" e "a noção de que os pais eram os melhores juizes dos interesses de seus filhos acabou por ser sobrepujada nessa esfera" (p. 215). Segundo Costa (2004), o Brasil vivia um período semelhante, mas a educação ainda estava voltada para a aristocracia brasileira. Neste período, o Brasil estava começando a educar sua elite, base- 
ando-se nos ideais europeus de educação. Somente no final do século XIX surgiram as primeiras creches para os filhos de escravas livres, e estas não foram instituídas como um direito da criança, mas como uma ajuda para os pais a fim de que eles pudessem trabalhar.

No século XX, no mundo ocidental em geral, várias determinações foram estabelecidas por especialistas em tais assuntos, por meio de conhecidas organizações internacionais que consideramos importantes e que nos dizem como as crianças devem ser cuidadas (UNICEF, OIT, OMS etc.). Mesmo no Brasil e em outros países que sofram com uma desigualdade social mais acentuada, nos quais essa separação criança/família é mais confusa, permeada por questões de sustento de casa e de cuidado com os irmãos menores enquanto os pais trabalham, a norma é a escolaridade obrigatória com currículos escolhidos e generalizados por especialistas.

A escola tornou-se o lugar idealizado da infância. Tem como objetivo a transmissão dos valores e dos conhecimentos da cultura, possibilitar a formação de vínculos e permitir que o sujeito se posicione como um cidadão. A criança que não estuda está fora da norma e, consequentemente, é desqualificada, perdendo sua característica infantil. Não será mais chamada de criança, mas sim de "mirim", "menor", "menino de rua", "portador de deficiência", entre outras denominações. 
As ideias expostas neste artigo, em uma proposta de subjetividade/laços sociais no campo da historicidade, mostram como o discurso social encaminha a infância para a escola. Ao configurar a pertinência social da criança no âmbito escolar, apontamos a ideia contemporânea "lugar de criança é na escola", como fator de inclusão/exclusão.

O mundo atual, diferente do que antecedia às grandes navegações, se configurou como multicultural. As diferenças trouxeram e trazem ainda inquietações. Curiosamente, a forma de lidar com isso foi a busca pelo padrão, a normatização e a exclusão, sustentados pelo discurso científico que se comprometeu com uma megalomania, em uma proposta de trocar Deus pela razão. A dialética igualdade/diversidade que se instalou no contato com os novos mundos, povos, religiões e culturas, além da construção das singularidades ao se tomar na modernidade o sujeito como prioridade, busca pelo discurso científico uma inclusão a qualquer preço, que na verdade gera uma exclusão mascarada. Incluir uma criança considerada diferente do normal em uma escola não é apenas matriculá-la e escolher uma sala de aula. É necessário um trabalho para que ela faça parte daquele grupo, daquela escola. Um trabalho muitas vezes criterioso, pois será necessário modificar algumas normas da sala ou até mesmo da instituição para que seja possível essa inclusão. Ao não se repensar no funcionamento das instituições, as crianças são matriculadas na escola, mas não fazem parte da mesma, e é comum se ouvir de crianças com necessidades especiais que passam a manhã no pátio da escola, separadas das outras. Elas continuam excluídas, a diferença que essa exclusão está acontecendo dentro da escola. Negam-se as diferenças pela tentativa de apagamento das singularidades: "todos são iguais e têm os mesmos direitos e oportunidades". Diferenças são incômodos a questionar as ideias vigentes de verdades absolutas.

Novos estudos já vêm sendo realizados há algum tempo com o intuito de mudar essa visão sobre a infância, pretendendo perceber as crianças como atores sociais plenos. A sociologia da infância, por exemplo, tem de certa forma tomado as rédeas desta discussão, revendo aspectos teóricos e metodológicos de seu objeto de pesquisa, procurando sair de uma visão dos adultos na compreensão da infância (Sarmento, 2002). Esperamos, com este trabalho, contribuir para a abertura de um espaço para se pensar como a subjetividade infantil pode ser afetada com esses discursos, sobre como as crianças se 
posicionam como sujeitos no contemporâneo, e sobre o que a psicologia pode acrescentar nisso. Sabemos ainda que estudos empíricos que se propõem a realmente escutar os pequenos enquanto sujeitos ainda são novidade, é mais comum achar pesquisas que discorrem sobre as crianças do que pesquisas que as considerem como participantes efetivas, com direito de serem escutadas em seus dizeres.

Enfim, vimos que discursos sociais são construções históricas e influenciam na visão que os sujeitos têm de si e do mundo. Assim como em outra época, Chico Caminhão pôde fazer parte de sua comunidade sem ser classificado como louco, houve um tempo em que lugar de criança não era necessariamente na escola e o ciclo de vida não era padronizado em etapas evolutivas de desenvolvimento. Ressaltamos que não nos posicionamos contra a educação formal e escolar, mas que podemos refletir sobre ela no sentido de não cristalizar idades certas para desenvolvimentos esperados, com foco em resultados predeterminados.

CHILDHOOD AND STANDARDIZATION: PLACE OF CHILD AND THE DISCOURSE ABOUT INCLUSION AND EXCLUSION

\section{Abstract}

This paper cover a bistorical path of childhood relationship. It discusses the ways of social inclusion and exclusion. The culture normalize the social discourse. We approach the current social discourse too, that it's very restrictive.
Index terms: childhood; normalizacion; inclusion; exclusion.

INFANCIA Y NORMALIZACIÓN: LUGAR DE LA CRIANZA Y EL DISCURSO SOCIAL DE LA INCLUSIÓN Y EXCLUSIÓN

\section{REsumen}

Este artículo aborda el recorrido de los modos de relación con la infancia en las diferentes épocas de la historia. Tiene por objetivo discutir las formas de inclusión y exclusión social del niño. La cultura promueve discursos sociales normalizadores. Abordamos el discurso actual, que impone un estrecho margen de normalidad.

Palabras clave: infancia; normalización; inclusión; exclusión.

\section{REFERÊNCIAS BIBLIOGRÁFICAS}

Ariès, P. (1986). A bistória social da criança e da família (2a ed.). Rio de Janeiro: Guanabara.

Bacon, F. V. S. A. (1984). Novun organum ou verdadeiras indicações acerca da interpretação da naturez̧a (Coleção “Os Pensadores”). São Paulo: Abril Cultural.

Badinter, E. (1985). Um amor conquistado: o mito do amor materno. Rio de Janeiro: Nova Fronteira.

Batalha, W. de S. C. (1968). A filosofia e a crise do homem. São Paulo: Editora Revista dos Tribunais.

Chauí, M. (2002). Introdução à história da filosofia. São Paulo: Companhia das Letras.

Costa, J. F. (2004). Ordem médica e norma familiar. Rio de Janeiro: Graal.

Descartes, R. (1983). Discurso do método (Coleção "Os Pensadores”). São Paulo: Abril Cultural.

Ferretti, M. C. G. (2004). O infantil: Lacan e a modernidade. Petrópolis: Vozes.

Figueiredo, L. C. (2002). A invenção do psicológico: quatro séculos de subjetivação 1500-1900 (5a ed.). São Paulo: Escuta. 


\title{
Artigo
}

Foucault, M. (1987). Vigiar e punir: nascimento da prisão. Petrópolis: Vozes.

Heywood, C. (2004). Uma história da infância: da Idade Média à época contemporânea no Ocidente. Porto Alegre: Artmed.

Lalande, A. (1999). Vocabulário técnico e crítico da filosofia. São Paulo: Martins Fontes.

Rousseau, J.-J. (1995). Emilio ou da educação. São Paulo: Martins Fontes.

Sarmento, M. J. (2002, abril). Infância, exclusão social e educação como utopia realizável. In Educação e sociedade, ano XXIII, n. 78.

Siqueira, H. S. G. Pós-modernidade, política e educação. Departamento de Sociologia e Política da UFSM. Recuperado em 24 nov. 2006, da Pós-modernidade, Política e Educação: < http://www.angelfire.com/sk/holgonsi>

Strathern, P. (1997). Descartes em 90 minutos. Rio de Janeiro: Jorge Zahar.

UNICEF (1989). A convenção sobre os direitos das crianças. Disponível em: <http:// www.unicef.pt/docs/pdf_publicacoes/convencao_direitos_crianca2004.pdf > . Acesso em: 30 jul. 2006.

\section{NOTAS}

1 Tal história é real e conhecida pelos antigos moradores da cidade, tendo sido contada por um deles: o pai de uma das pesquisadoras.

\author{
regina@ecpc-ce.com.br \\ luana_tm@hotmail.com / \\ luanatm@gmail.com \\ gezinha@gmail.com \\ elisaparentecosta@hotmail.com
}

Recebido em outubro/ 2008. Aceito em fevereiro/ 2009. 